\title{
SEASONAL COMPARISON OF VELOCITY OF THE EASTERN TRIBUTARY GLACIERS, AMERY ICE SHELF, ANTARCTICA, USING SAR OFFSET TRACKING
}

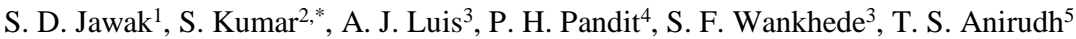 \\ ${ }^{1}$ Svalbard Integrated Arctic Earth Observing System (SIOS), SIOS Knowledge Centre, University Centre in Svalbard (UNIS), P.O. \\ Box 156, N-9171, Longyearbyen, Svalbard, Norway; shridhar.jawak@gmail.com \\ ${ }^{2}$ Centre for Land Resource Management, Central University of Jharkhand, Ranchi - 835205, India; shubh30195@ gmail.com \\ ${ }^{3}$ Earth System Science Organization- National Centre for Polar and Ocean Research, Ministry of Earth Sciences, Government of \\ India, Headland Sada, Vasco-da -Gama, Goa 403804, India; alvluis@ ncaor.gov.in; swankhede436@gmail.com \\ ${ }^{4}$ National Bureau of Soil Survey and Land Use planning (NBSS \& LUP) - Indian Agriculture Research Institute (IARI), New Delhi, \\ India; sh.prashantpandit@gmail.com \\ ${ }^{5}$ University of Twente, Faculty ITC, P. O. Box 217, 7500 AE Enschede, Netherlands; a.tharaventhedathsomadas@student.utwente.nl
}

KEY WORDS: Amery Ice Shelf, Glacier Surface Velocity, Offset Tracking, SAR, Remote Sensing

\begin{abstract}
:
Antarctica and Greenland are two major Earth's continental ice shelves which play an important role in influencing Earth's energy balance through their high albedo. The ice sheets comprise of grounded ice or the continental glaciers and their associated ice shelves. Surface velocity is an important parameter that needs to be monitored to understand the glacier dynamics. Marine terminating glaciers have higher velocity than land terminating glaciers. Therefore, ice shelves are generally observed to have higher velocity as compared to continental glaciers. The focus of this study is Amery ice shelf (AIS) which is the third largest ice shelf located in east Antarctica terminating into the Prydz Bay on the eastern Antarctica. The surface ice-flow velocity of AIS is very high compared to its surrounding glaciers which flows at a rate of 1400 ma-1 and drains about $8 \%$ of the Antarctic ice sheet. AIS is fed by different glaciers and ice streams at the head, as well as from the western and eastern side of the ice shelf before it terminates into the ocean. The primary objective of this study was to compute velocity of the eastern tributary glaciers of AIS using SAR from Sentinel-1 data. The secondary objective was to compare the winter and summer velocities of the glaciers for 2017-2018. The offset tracking method has been applied to the ground range detected (GRD) product obtained from Sentinel-1 satellite. This method is suitable for regions with higher glacier velocity where interferometry is generally affected by the loss of coherence. The offset tracking method works by tracking the features on the basis of another feature and calculates the offset between the two features in the images. Two tributary glaciers near the Clemence massif and another glacier near the Pickering Nunatak feed into this ice shelf from the eastern glacial basin region that drains ice from the American Highland, east Antarctica. The glaciers near the Clemence massif showed low annual velocity which ranged from 100 ma-1at the head to $\sim 300$ ma-1 near the end of the glacier, where it merges with AIS. The glaciers flowing near the Pickering Nunatak exhibited moderate velocity ranging from $150 \mathrm{ma}-1$ at its head and reaching up to 450 ma -1 near the tongue. The summer velocity (March 2018) was observed to be higher than the velocity in winter (July 2017) and the difference between the summer and the winter velocities was found to be between 50 ma-1 and 130 ma-1. The results for the velocity were obtained at 120 $\mathrm{m}$ resolution and were compared with the previous MEaSUREs (Making Earth System Data Records for Use in Research Environments) yearly velocity at $450 \mathrm{~m}$ and $1 \mathrm{~km}$ resolution provided by National Snow and Ice Data Center portal. The results were evaluated using statistical measure- bias and the accuracy was derived using the root mean square error. The bias did not exceed 20 ma-1for the three glaciers and the accuracy was observed to be more than $85 \%$ for most of the regions. The accuracy of the results suggests that the offset tracking technique is useful for future velocity estimation in the regions of high glacier velocity.
\end{abstract}

\section{INTRODUCTION}

The ice and snow in the Polar Regions play a crucial role in Earth's radiation budget as the cryosphere reflects about $90 \%$ of the incoming solar radiation (Jawak and Luis, 2014). The continental shelves of Antarctica and Greenland are almost completely covered by ice (Jawak et al., 2018). In the southern hemisphere Antarctica hosts larger ice mass and in the northern hemisphere Greenland contains relatively less ice mass, both of which could contribute to sea level rise of $66 \mathrm{~m}$, if completely melted. Most of the cryospheric regions are situated in severe weather conditions and accessibility to these regions is limited due to their rough terrain, harsh weather conditions, sometimes all year round and high logistic cost. The inaccessibility due to various factors make remote sensing the best and most affordable technique that could be used for monitoring different dynamics of the glaciers in these regions (Jeong et al., 2017; Jawak et al., 2017; Pandit et al., 2017; Jawak et al., 2018). The availability of satellite remote sensing technology and its progress in recent decades has enhanced our capability to monitor these regions at regular time intervals over a long period of time (Jawak and Luis, 2014).

The mass balance of glaciers is pivotal to understanding the accumulation of ice and its subsequent drain into the sea due to ablation (Lugli and Vittuari, 2017). Various factors that cause glacier ablation are surface melt, surface melt water runoff, sublimation, avalanching and windblown snow. The velocity of

\footnotetext{
* Corresponding author.
} 
the outlet glaciers partially determines the mass balance of the glacier body (Joughin et al., 2004). The ice shelves and the glacier ice tongues which terminate into the sea drain most of the ice from the Antarctic ice sheet (Fricker et al., 2002). Using Synthetic Aperture Radar (SAR) and offset tracking technique, accurate glacier surface velocity for fast flowing glaciers can be estimated. This technique is also effective for scenarios involving where large temporal differences in data acquisition (Lugli and Vittuari, 2017).

\section{STUDY AREA AND DATA}

The Antarctic ice sheet comprises of the eastern and the western ice sheets divided by the Transantarctic Mountains. The study was focused on two of the glaciers in the East tributary glacial basin of the Amery Ice Shelf (AIS), East Antarctic (Figure 1). AIS is the third largest ice shelf covering around $16 \%$ of the East Antarctic ice sheet (King et al., 2007) which drains around $8 \%$ of the total ice mass of the Antarctic ice sheet. It is one of the fast flowing glaciers of Antarctica. It is fed by many tributary glaciers with two major glaciers, each from the east and west, as well as three glaciers from the head of the ice shelf.

These two glaciers join prior to the mid-section of the ice shelf and are the major contributors to the ice shelf from the eastern side. One glacier joins the ice shelf near the Clemence Massif and the other joins the ice shelf near the Pickering Nunatak. Both of the glaciers drain the ice from the American Highland to join the ice shelf and act as the major contributors to the ice shelf from the eastern side of the shelf.

The Antarctic summer lasts for 6 months from October to March and the winter from April to September. Optical data acquisition is not possible during the winter season due to darkness. Hence, for the comparison of winter and summer and winter velocities, microwave satellite data is necessary, as it is independent of clouds and lights. The velocity of the eastern tributary glaciers of the AIS was estimated using Sentinel-1 (Sentinal-1a and Sentinel-1b) microwave synthetic aperture radar (SAR) Ground Range Detected (GRD) product released by European Space Agency's (ESA) Copernicus programme. The single satellite provides a temporal resolution of 12 days whereas combining the twin satellites of the Sentinel-1, the temporal resolution decreases to 6 days allowing a regular assessment of the surface velocity of AIS without confronting any temporal decorrelation due to the faster movement of the surface ice.

\begin{tabular}{|c|c|c|c|}
\hline Season & Acquisition 1 & Acquisition 2 & Path/Frame \\
\hline $\begin{array}{c}\text { Winter } \\
\text { (July 17) }\end{array}$ & $15-07-2017$ & $21-07-2017$ & $3 / 839$ \\
\cline { 2 - 4 } & $15-07-2017$ & $21-07-2017$ & $3 / 844$ \\
\hline $\begin{array}{c}\text { Summer } \\
\text { (March } \\
\text { 18) }\end{array}$ & $06-03-2018$ & $12-03-2018$ & $3 / 839$ \\
\cline { 2 - 4 } & $18-03-2018$ & $24-03-2018$ & $3 / 844$ \\
\hline
\end{tabular}

Table 1. Acquisition details of Sentinel-1 data used in the study

Table 1 provides information on the data that was used for the surface velocity estimation of the eastern tributary glaciers as well as for the comparison of the seasonal (winter and summer) velocity. The data was acquired in the Interferometric Wide swath (IW) mode which has a resolution of $20 \mathrm{~m}$ in the range direction and $22 \mathrm{~m}$ in the azimuth direction. The pixel spacing of the IW mode for the GRD product is $10 \mathrm{~m}$ in both range and azimuth direction. Figure 2 shows the extent of the two data frames used for the study area.
Along with the Sentinel-1 data, the Digital Elevation Model (DEM) generated from Radarsat Antarctic Mapping Project (RAMP) was used in the study. Of the different resolutions of the DEM generated from the RAMP project we used the highest resolution of $200 \mathrm{~m}$. The availability of other higher resolution DEM in the area is limited due to its geographical location which is less frequently covered by other satellites.

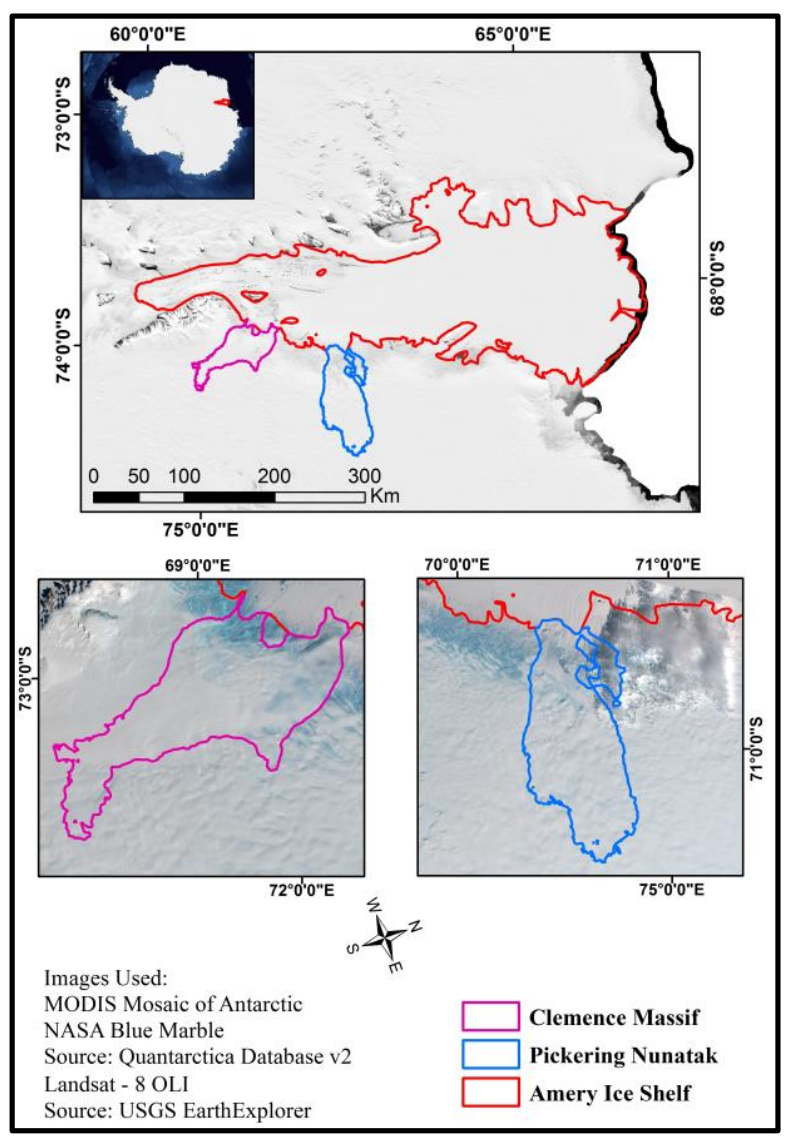

Figure 1. Geographical location of the study area.

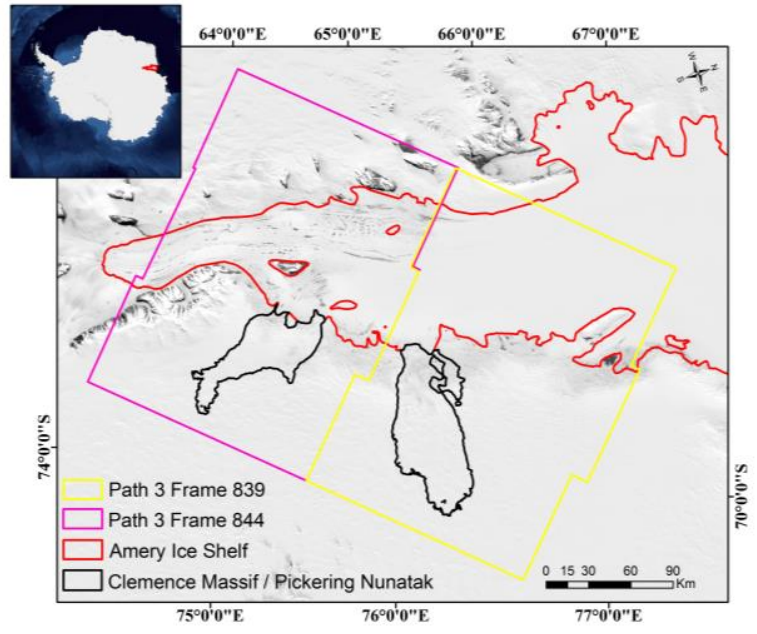

Figure 2. Map showing extent of Sentinel-1 data used for the study. 


\section{METHODOLOGY}

The methodology for the whole study was divided into two parts which comprises of image processing for velocity estimation and accuracy assessment.

\subsection{Image Processing and Results}

On account of the high surface flow velocity of the AIS and its tributary glaciers, the estimation of velocity considering unwrapped phase SAR using interferometric techniques is less reliable due to the lack of coherence needed for precise calculations, and due to unavailability of ground control points for phase calibration in areas that are enveloped by ice (Lugli and Vittuari, 2017). The interferometric technique measures the movement along the line of sight efficiently (Tong et al., 2018; Joughin et al., 2010), which acts as a limitation in most of the regions of the AIS as the ice shelf flows along the azimuthal direction.

Offset tracking as an alternative technique to interferometric SAR was introduced to overcome the limitations of rapid and incoherent flow (Strozzi et al., 2002). Co-registration offset tracking is less accurate than interferometry but provides displacement measurements in the azimuth as well as in the range (line of sight) direction (Lugli and Vittuari, 2017; Strozzi et al., 2002).

The offset tracking method incorporates various steps for final velocity estimation (Figure 3 ). The first and the most important step for deriving velocity starts from the selection of suitable image pairs i.e., pre- and post- event images. The image selection is then followed by application of precise orbital data to the image acquired for precise and accurate location and displacement observation. After applying the orbital data to the acquired images, the master and the slave image (pre-event and post-event respectively) is co-registered into a single stack with the help of DEM. The RAMP DEM is used for the co-registration of the two images. Co-registration is a necessary step as it ensures the ground targets from a stationary scene contributes to the same (range, azimuth) pixel in both master and slave images. The DEM helps to co-register on the basis of the geometry.

The co-registration is then followed by offset tracking that estimates the movement of glacier surfaces between master and slave images in both slant-range and azimuthal direction. The Ground Control Points (GCP) are selected automatically through the process and cross-correlation is performed on selected GCPs in master and slave images. The offset tracking produces a displacement map combining the azimuthal and range displacement. The displacement map obtained as a raster image is further used to produce the output velocity map that shows the velocity of the glacier between the two time periods of the image acquisition.

\subsection{Accuracy Assessment}

The accuracy assessment was performed using two methods. The reference for the accuracy assessment was taken from the previously derived velocity map of the Antarctic ice sheet acquired from the National Snow and Ice Data Centre (NSIDC) portal. The NSIDC portal has yearly averaged velocity products of complete Antarctica obtained from study conducted by Mouginot et al. (2017). The accuracy of the obtained results was measured on the basis of biasness from the previous results as well as by calculation of the root mean square error (RMSE) of the result.
Image Processing and Velocity computation

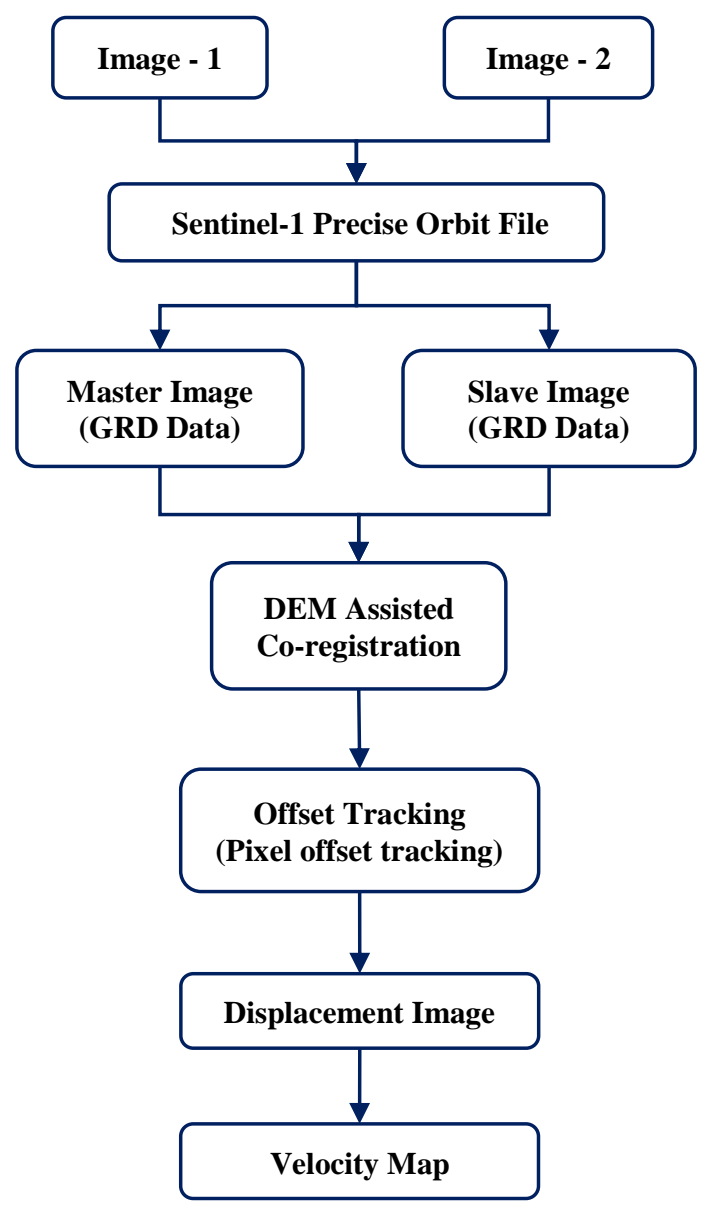

Accuracy assessment

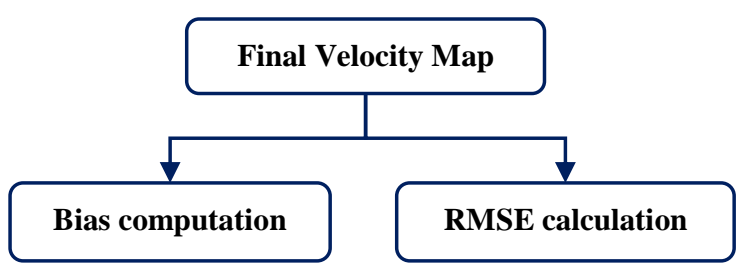

Figure 3. Flowchart of methodology adopted for the study.

\section{RESULTS AND DISCUSSION}

The velocity was obtained for the eastern tributary glaciers of the AIS for both summer and winter seasons (Figure 4). The results obtained using the offset tracking method agreed well with the previously derived measurements. 


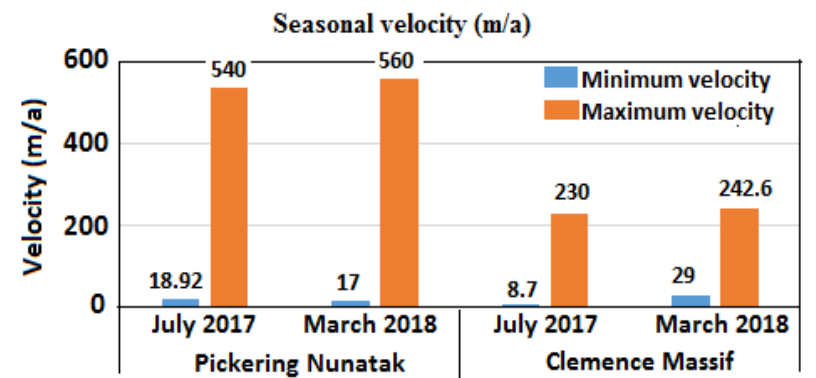

Figure 4. Histograms of maximum and minimum velocity during summer and winter of the eastern tributary glaciers.

The maximum velocity during summer near the Clemence Massif was observed to be $242 \mathrm{~m} / \mathrm{a}$, whereas in winter the maximum velocity was observed to be $230 \mathrm{~m} / \mathrm{a}$. Near the Pickering Nunatak, the maximum velocity observed during the summer season was $560 \mathrm{~m} / \mathrm{a}$, whereas during the winter season, the maximum velocity was observed to be around $540 \mathrm{~m} / \mathrm{a}$. (Figure 4). The velocity near the Clemence Massif in winter as well as summer did not exhibit much difference except that during the summer the velocity was higher near the mouth of the glacier where its meets the ice shelf (Figure 5).

The velocity of the glaciers near the Clemence Massif increased as it moved towards the ice shelf. The glacier joins the ice shelf at an inclined angle along the flow direction which also adds up to the velocity of the glacier near its mouth. Since the AIS exhibited a very high velocity as compared to its eastern tributary glacier, and the glacier near the Pickering Nunatak meets the ice shelf almost perpendicular to its motion of flow, the velocity near the mouth of the glacier was observed to be low in summer (Figure 6).

The velocity near the Pickering Nunatak during the summer and the winter was higher at the mouth of the glacier, but decreased where it connects with the ice shelf. (Figure 6) The summer velocity was observed to be slightly lower than the winter velocity near the terminal region of the glacier.

\begin{tabular}{|c|c|c|c|}
\hline Glacier & Month & BIAS & RMSE (m/yr.) \\
Pickering & July-17 & 9.42 & 26.35 \\
\cline { 2 - 4 } Nunatak & March-18 & 13.59 & 22.67 \\
\cline { 2 - 4 } Clemence & July-17 & 20.67 & 24.95 \\
\cline { 2 - 4 } Massif & March-18 & 26.43 & 29.83 \\
\hline
\end{tabular}

Table 2: Accuracy of the derived results.

The accuracy of the obtained velocity using offset tracking method was between $80 \%$ and $90 \%$. The bias of the result was not more than $14 \mathrm{~m} / \mathrm{a}$. during the winter season and within $27 \mathrm{~m} / \mathrm{a}$ during the summer season. The RMSE of the results was also not more than $30 \mathrm{~m} / \mathrm{a}$ in the regions with moderate flow velocity of about 200 to $500 \mathrm{~m} / \mathrm{a}$. (Table 2).

\section{Surface velocity near Clemence Massif} $69^{\circ} 0^{\prime} \mathrm{E}$ $69^{\circ} 30^{\prime} \mathrm{E}$
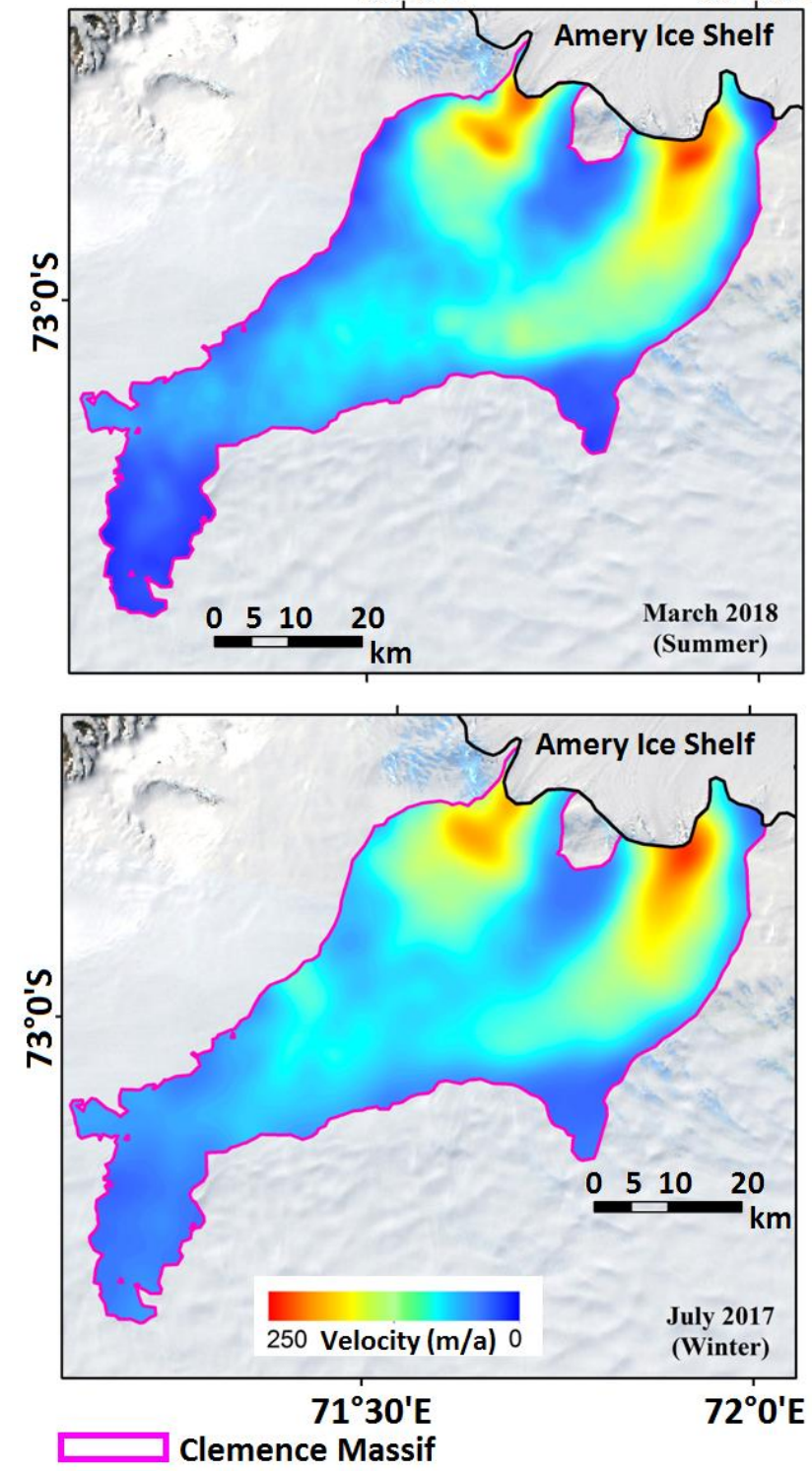

Figure 5. Summer and winter velocity near the Clemence Massif, East Antarctica

The velocities derived in this study is compared with previously derived and published results of Mouginot et al., 2012, Rignot et al., 2017, Mouginot et al., 2017. The derived velocity were comparable to the previous studies and the accuracy of the results were upto $90 \%$. 


\section{Surface velocity near Pickering Nunatak}
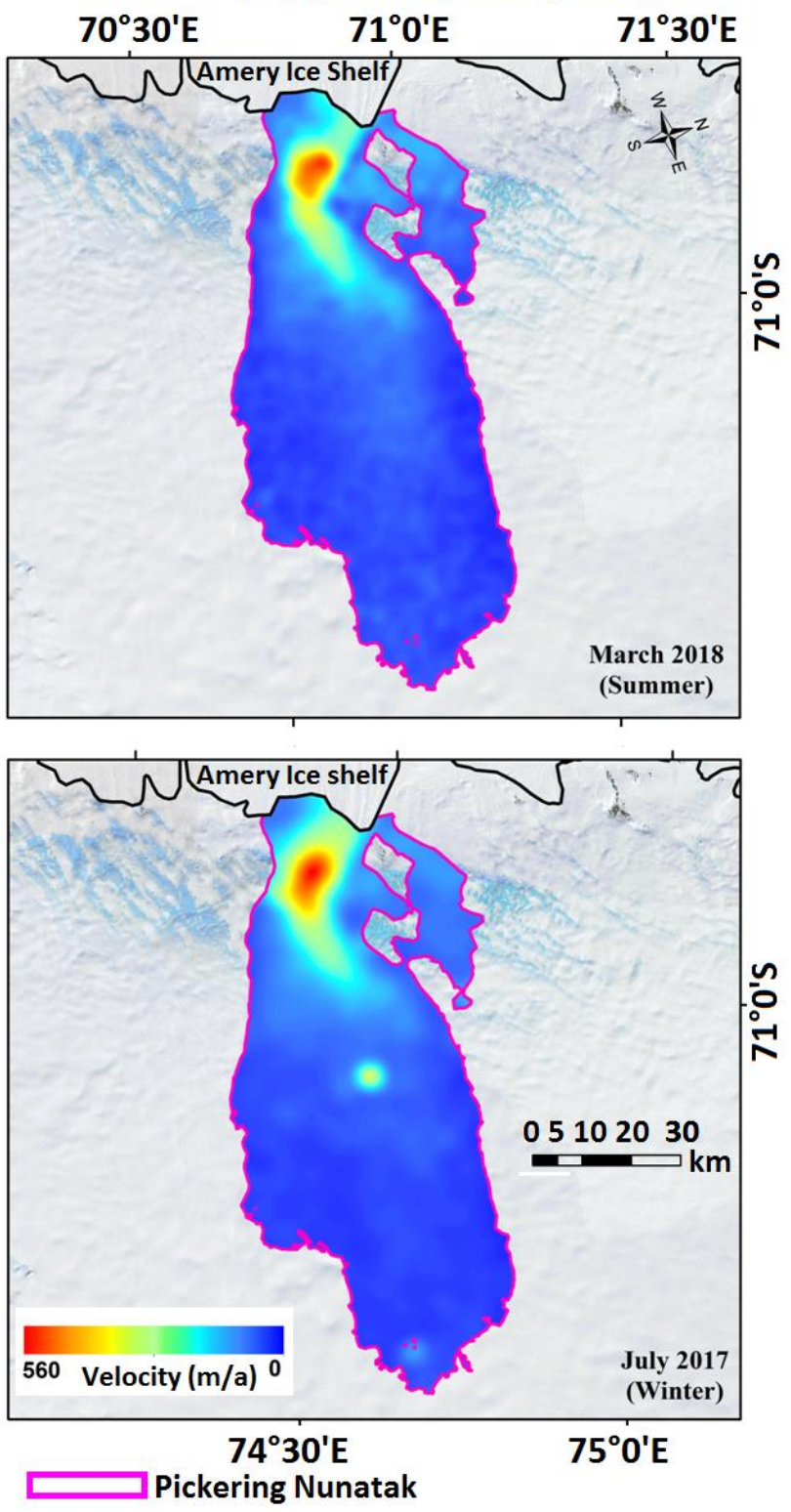

Figure 6. Summer and winter velocity near the Pickering Nunatak, East Antarctica.

\section{CONCLUSION}

The offset tracking method is useful to find the surface velocity of the glaciers having moderate to high flow velocity. The temporal decorrelation is less observed in offset tracking method as compared to interferometry. SAR datasets is an assert to estimate surface velocity throughout the year as the year round measurements using optical remote sensing data is not possible due to complete darkness during winter. The difference between seasonal velocities was not very large, as most of Antarctica is covered by ice throughout the year. The velocity at the mouth of the glacier near the Clemence Massif increased as it flows along the flow direction of the glacier in the AIS. The velocity near the Pickering Nunatak decreased at its mouth due to increase in across motion of glacier flow with the AIS. The accuracy obtained using the offset tracking method matched well with previously derived velocity of the AIS that comprised various methods and different data sets. The annual velocities of the previous studies were the most stable data available to validate the results.

\section{ACKNOWLEDGEMENTS}

The authors thank European Space Agency for providing access to the open source SAR images of Sentinel-1 that has been used in the study. We would also like to acknowledge Dr. M. Ravichandran, Director, ESSO-NCPOR for his encouragement and motivation for the project. The entire experiment and validation were conducted at the ESSO-NCPOR. The lead author (S.D.J) has recently moved to SIOS, Longyearbyen, Norway.

\section{REFERENCES}

Fricker, H., Allison, I., Craven, M., Hyland, G., Ruddell, A., Young, N., Coleman, R., King, M., Krebs, K. and Popov, S., 2002. Redefinition of the Amery Ice Shelf, East Antarctica, grounding zone. In: Journal of Geophysical Research, 107(B5). DOI: https://doi.org/10.1029/2001JB000383

Jawak, S.D. and Luis, A.J., 2014. Synergetic merging of Cartosat-1 and RAMP to generate improved digital elevation model of Schirmacher oasis, east Antarctica. In: ISPRS International Archives of the Photogrammetry, Remote Sensing and Spatial Information Sciences, XL-8, pp.517-524. DOI: https://doi.org/10.5194/isprsarchives-XL-8-517-2014

Jawak, S.D, Kumar, S., Luis, A.J, Bartanwala, M., Tummala, S. and Pandey, A.C., 2018. Evaluation of Geospatial Tools for Generating Accurate Glacier Velocity Maps from Optical Remote Sensing Data. In: Proceedings, 2(7), p.341. DOI: https://doi.org/10.3390/ecrs-2-05154

Jawak, S.D., Pandit, P., Luis, A.J., Malik, K., Sinha, V.S.P., 2017. Derivation of velocity of the Potsdam Glacier, east Antarctica using SAR interferometry. In: Proceedings of the 38th Asian Conference on Remote Sensing (ACRS 2017), Delhi, India, 23-27 October 2017; Available online: http://www.a-a-rs.org/acrs/administrator/components/com_jresearch/files/public ations/94.pdf.

Jeong, S., Howat, I., Ahn, Y., 2017. Improved Multiple Matching Method for Observing Glacier Motion with Repeat Image Feature Tracking. In: IEEE Transaction of Geoscience and Remote Sensing 2017, 55, 2431-2441. DOI: https://doi.org/10.1109/TGRS.2016.2643699

Joughin, I., Abdalati, W. and Fahnestock, M., 2004. Large fluctuations in speed on Greenland's Jakobshavn Isbræ glacier. In: Nature, 432(7017), pp.608-610. DOI: https://doi.org/10.1038/nature03130

Joughin, I., Smith, B. and Abdalati, W., 2010. Glaciological advances made with interferometric synthetic aperture radar. In: Journal of Glaciology, 56(200), pp.1026-1042. DOI: https://doi.org/10.3189/002214311796406158

King, M., Coleman, R., Morgan, P. and Hurd, R., 2007. Velocity change of the Amery Ice Shelf, East Antarctica, during the period 1968-1999. In: Journal of Geophysical Research, 112(F1). DOI: https://doi.org/10.1029/2006JF000609

Liu, H., K. C. Jezek, B. Li, and Z. Zhao., 2015. Radarsat Antarctic Mapping Project Digital Elevation Model, Version 2. Boulder, Colorado USA. NASA National Snow and Ice Data 
Center Distributed Active Archive Center. DOI: https://doi.org/10.5067/8JKNEW6BFRVD

Lugli, A. and Vittuari, L., 2017. A polarimetric analysis of COSMO-SkyMed and RADARSAT-2 offset tracking derived velocities of David-Drygalski Glacier (Antarctica). In: Applied Geomatics, 9(1), pp.43-52. DOI: https://doi.org/10.1007/s12518016-0181-8

Mouginot, J., Scheuchl, B., and Rignot, E., 2017, MEaSUREs Annual Antarctic Ice Velocity Maps 2005-2017, Version 1. [Indicate subset used]. Boulder, Colorado USA. In: NASA National Snow and Ice Data Center Distributed Active Archive Center. DOI: https://doi.org/10.5067/9T4EPQXTJYW9.

Mouginot, J., Scheuchl, B. and Rignot, E., 2012. Mapping of Ice Motion in Antarctica Using Synthetic-Aperture Radar Data. In: Remote Sensing, 4(9), pp.2753-2767. DOI: https://doi.org/10.3390/rs4092753

Pandit, P.H., Jawak, S.D., Luis, A.J., 2017. Deriving Velocity of the Polar Record Glacier, East Antarctica Using SAR Interferometry. In: Science and Geopolitics of Himalaya, Arctic \& Antarctic-Focusing on Climate Change" (SaGHAA 2017), 30 November-1 December 2017; JNU Convention Centre, Jawaharlal Nehru University: New Delhi, India, 2017.

Rignot, E., Mouginot, J., and Scheuchl, B., 2017. MEaSUREs InSAR-Based Antarctica Ice Velocity Map, Version 2. Boulder, Colorado USA. In: NASA National Snow and Ice Data Center Distributed Active Archive Center.

Rignot, E., Mouginot, J. and Scheuchl, B., 2011. Ice Flow of the Antarctic Ice Sheet. In: Science, 333(6048), pp.1427-1430. DOI: https://doi.org/10.1126/science.1208336

Strozzi, T., Luckman, A., Murray, T., Wegmüller, U. and Werner, C., 2002. Glacier motion estimation using SAR offsettracking procedures. In: IEEE Transactions on Geoscience and Remote Sensing, 40(11), pp.2384-2391. DOI: https://doi.org/10.1109/TGRS.2002.805079

Tong, X., Liu, S., Li, R., Xie, H., Liu, S., Qiao, G., Feng, T., Tian, Y. and Ye, Z., 2018. Multi-track extraction of two-dimensional surface velocity by the combined use of differential and multipleaperture InSAR in the Amery Ice Shelf, East Antarctica. In: Remote Sensing of Environment, 204, pp.122-137. DOI: https://doi.org/10.1016/j.rse.2017.10.036 